\title{
Osteoporosis in acute fractures of the cervical spine: the role of opportunistic CT screening
}

\author{
Osa Emohare, MBBS, PhD, ${ }^{1}$ Alison Dittmer, BS, ${ }^{2}$ Robert A. Morgan, MD, ${ }^{3}$ Julie A. Switzer, MD, ${ }^{3,4}$ \\ and David W. Polly Jr., MD ${ }^{3}$
} Departments of ${ }^{1}$ Neurological Surgery and ${ }^{4}$ Orthopaedic Surgery, Regions Hospital, St. Paul; ${ }^{2}$ University of Minnesota Medical
School, Minneapolis; and ${ }^{3}$ Department of Orthopaedic Surgery, University of Minnesota, Minneapolis, Minnesota

\begin{abstract}
OBJECT Recently published data make it possible to generate estimates of bone mineral density (BMD) by using CT attenuation; this innovation can save time and reduce costs. Although advanced age is associated with reduced BMD, especially in patients with a fracture of C-2, relatively few patients ever undergo formal dual x-ray absorptiometry studies. To the authors' knowledge, this is the first study to assess the utility of this technique in elucidating BMD in patients with an acute fracture of the cervical spine.
\end{abstract}

METHODS Patients who presented to a Level I trauma center with an acute fracture of the cervical spine and underwent abdominal (or L-1) CT scanning either at admission or in the 6 months before or after the injury were evaluated. Using a picture-archiving and communication system, the authors generated regions of interest of similar size in the body of L-1 (excluding the cortex) and computed mean values for CT attenuation. The values derived were compared with threshold values, which differentiate between osteoporotic and nonosteoporotic states; age-stratified groups were also compared.

RESULTS Of the 91 patients whose data were reviewed, 51 were $<65$ years old (mean 43.2 years) and 40 were $\geq 65$ years old (mean 80.9 years). The overall mean CT attenuation values (in Hounsfield units [HU]), stratified according to age, were 193.85 HU for the younger cohort and 117.39 HU for the older cohort; the result of a comparison between these two values was significant $(p<0.001)$.

CONCLUSIONS Using opportunistic CT scanning, this study demonstrates the relative frequency of osteoporosis in acute fractures of the cervical spine. It also objectively correlates overall BMD with the known higher frequency of C-2 fractures in older patients. This technique harnesses the presence of opportunistic CT scans of the abdomen, which potentially reduces the need for the extra time and cost that may be associated with dual x-ray absorptiometry scanning. http://thejns.org/doi/abs/10.3171/2014.10.SPINE14233

KEY WORDS aging; bone density; bone fractures; cervical spine; geriatrics; odontoid process; osteoporosis; spine; degenerative

$\mathrm{T}$ HE ability of the cervical spine to bear weight, move in 6 degrees of freedom, ${ }^{34}$ and provide passage for vascular and neural structures makes it the most complex articular system in the body. ${ }^{9}$ Much like bone in other parts of the spine, the cervical spine is affected by physiological processes such as aging and degeneration. In other parts of the spine, when fractures related to aging occur, the risk of future fractures increases. ${ }^{10}$

As the population of the developed world ages, it is like- ly that fractures associated with aging will become more common. The effect of aging is readily demonstrated in the cervical spine. As people get older and their bone density decreases, fractures of the C-2 vertebra, in particular, increase in frequency. ${ }^{26,27,32} \mathrm{~A}$ review of older patients who sustained fractures of $\mathrm{C}-2$ found, on the basis of subjective radiographic assessments of the $\mathrm{C}-2$ vertebra, that more than half of the patients had osteoporosis. ${ }^{11,12}$

Older patients also tend to sustain relatively severe cer-

ABBREVIATIONS BMD = bone mineral density; $D X A=$ dual-energy x-ray absorptiometry; $\mathrm{HU}=$ Hounsfield unit; $\mathrm{QCT}=$ quantitative $\mathrm{CT} ; \mathrm{ROI}=$ region of interest. SUBMITTED May 5, 2014. ACCEPTED October 23, 2014.

INCLUDE WHEN CITING Published online April 10, 2015; DOI: 10.3171/2014.10.SPINE14233.

DISCLOSURE The authors report no conflict of interest concerning the materials or methods used in this study or the findings specified in this paper. 
vical spine injury from seemingly minor trauma, which usually involves falling from standing height or lower or injury occurring at a relatively low velocity. ${ }^{13,25}$ One of the main factors to which this phenomenon has been attributed is osteoporosis. ${ }^{2}$ In terms of absolute frequency, cervical spine fractures are more common in the elderly than in younger adults. Lomoschitz et al. ${ }^{13}$ outlined a constellation of factors that have been suggested as being responsible for this observation. ${ }^{20}$ These factors include the propensity of the elderly to sustain falls, the increased per-mile risk of motor vehicle crashes in the elderly, and biomechanical attrition due to age-related osteoporosis.

Although formal dual-energy x-ray absorptiometry (DXA) scanning is recommended for all women aged $>$ 65 years and all men aged $>70$ years, less than $33 \%$ of women and 5\% of men undergo screening after fractures caused by a low-velocity mechanism..$^{15}$ Despite the fact that sustaining a fracture caused by a low-velocity mechanism suggests an underlying impairment in bone quality, these low proportions are noteworthy.

Recently published data showed that osteoporosis can be diagnosed with CT attenuation using values derived from CT scans of the abdomen ordered for reasons other than the measurement of bone mineral density (BMD). ${ }^{23}$ Given the increase in comorbid conditions associated with increasing age, imaging is performed frequently. Each year in the United States, more than 80 million CT scans are acquired, ${ }^{15}$ many of which carry potentially useful information about a patient's BMD-information that has not been harnessed until now. Although the authors of studies have commented on localized bone loss after fracture of C-2,,$^{11,12}$ no studies have correlated fractures in this or other levels of the cervical spine with the frequency of "objectively" defined osteoporosis based on DXA results. This study was designed to use CT attenuation at L-1 to outline the frequency of osteoporosis in patients who present with acute fractures of the cervical spine and to determine the role of a patient's age in this relationship.

\section{Methods}

The HealthPartners Institutional Review Board approved this study.

Using case logs, we retrospectively identified patients from our Level I trauma center who had sustained a fracture of the cervical spine and who underwent abdominal CT scaning (or other CT scanning that included a view of the L-1 vertebra) between June 2010 and December 2012. The patients were then stratified according to age $(<65$ vs $\geq 65$ years). Any patient with a fracture through L-1 was excluded. For each patient with a CT scan of the abdomen (or other CT scan of L-1), we determined whether the scan had been performed in the 6 months before or after the cervical spine fracture, because that is the time frame for which this method was validated. ${ }^{23}$ Qualifying CT scans were reviewed, and a region of interest (ROI) was selected over the body of the L-1 vertebra. We ensured that the cortex of the vertebra was not captured in the ROI, because it artificially inflates $\mathrm{CT}$ attenuation. For each patient, the maximum, minimum, and mean $\mathrm{CT}$ attenuation values (in Hounsfield units [HU]) over the ROI were recorded (Figs. 1 and 2). The CT scanners used for the measure-

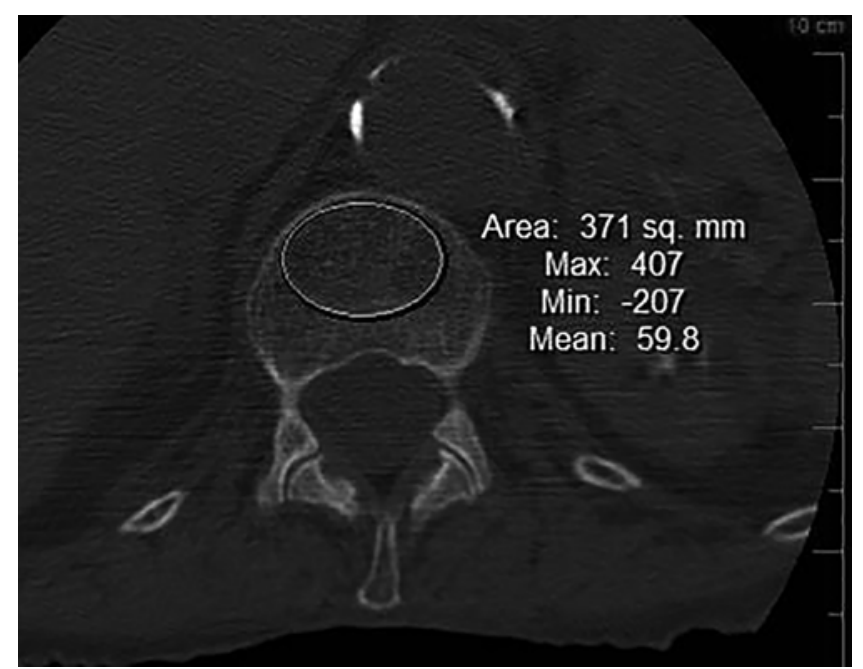

FIG. 1. An ROI showing a reduced mean $\mathrm{CT}$ attenuation value of $59.8 \mathrm{HU}$.

ments (GE LightSpeed 12-Speed and GE VCT 64-Slice [GE Healthcare]) were calibrated daily during the period in which the scans were performed.

In addition to measuring the levels of $\mathrm{CT}$ attenuation at L-1 in patients with injuries at all levels of the cervical spine combined, we identified a subgroup of patients who were aged $\geq 65$ years and had a fracture of the C-2 vertebra. We further stratified this group into those with and those without Type II odontoid fractures, and we measured the CT attenuation at L-1 in each patient in these 2 groups (Fig. 3).

Previously published threshold values were used in the retrospective diagnosis of osteoporosis. ${ }^{23}$ Three thresholds were evaluated: 1) $\leq 110$ and $>110 \mathrm{HU}$, selected to achieve approximately $90 \%$ specificity in differentiating osteoporosis from nonosteoporosis; 2) $\leq 135$ and $>135$ $\mathrm{HU}$, selected for balanced sensitivity and specificity in differentiating between osteoporosis and nonosteoporosis; and 3) $\leq 160$ and > $160 \mathrm{HU}$, selected for $90 \%$ sensitivity in differentiating between osteoporosis and nonosteoporosis.

Thresholds were also set in the index publication to differentiate normal bone density from low bone density. ${ }^{23}$ They were set for approximately $90 \%$ sensitivity, balanced sensitivity and specificity, and approximately $90 \%$ specificity at 1$) \leq 135$ and $>135 \mathrm{HU}, 2) \leq 160$ and $>160 \mathrm{HU}$, and 3) $\leq 190$ and > $190 \mathrm{HU}$, respectively.

Regressions were generated to obtain coefficients of correlation with the aim of elucidating the ability of CT attenuation to capture age-related declinations in BMD. This regression was done for fractures at the level of C-2, subaxial cervical spine fractures, and all cervical spine fractures combined. These regressions were generated using Microsoft Excel.

The mean $\mathrm{HU}$ values for $\mathrm{CT}$ attenuation in patients aged $\geq 65$ years were compared with those of the younger patients by using a Student t-test (Microsoft Excel). The proportion of patients in each of the threshold groups in which osteoporosis was differentiated from nonosteoporosis in patients aged $\geq 65$ years was compared with that of 


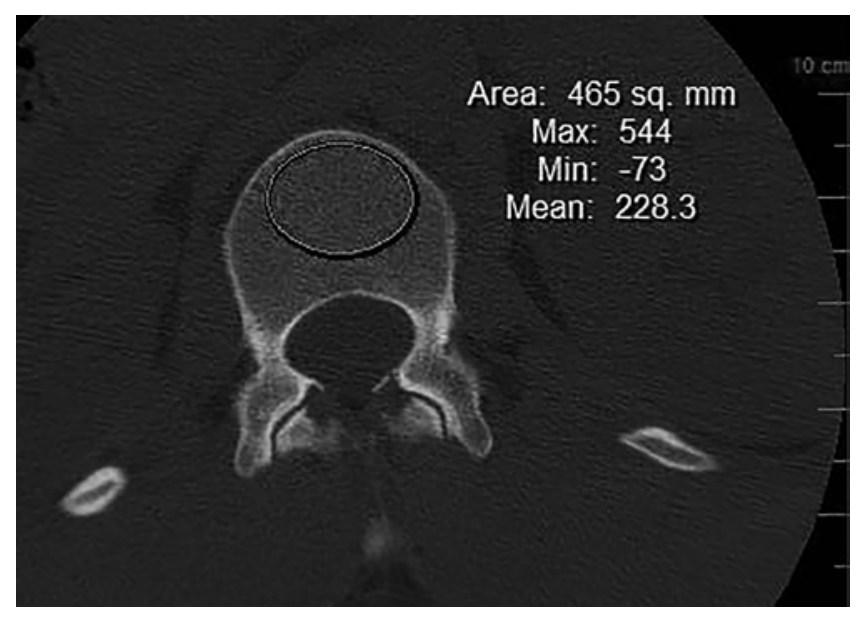

FIG. 2. An ROI showing a normal mean CT attenuation value of $228.3 \mathrm{HU}$

younger patients using the 2-tailed Fisher exact test (http:// research.microsoft.com/en-us/um/redmond/projects/ mscompbio/fisherexacttest/).

\section{Results}

A total of 152 patients with 226 fractures presented in the time frame of this study. Seventy-five patients were aged 18-64 years and presented with a total of 124 fractures, and 77 patients were aged $\geq 65$ years and presented with a total of 102 fractures. A high-velocity mechanism of injury was most common in the younger group, with motor vehicle collisions accounting for the fractures in 46 patients $(61 \%)$, whereas in the older group, a low-velocity mechanism (fragility fractures) was the most common mechanism by which injury occurred, with 40 patients $(52 \%)$ falling from standing height or lower.

Of the aforementioned totals, 91 patients with a cervical spine fracture also had the requisite CT scan showing the L-1 vertebra acquired within the specified time frame. It was these 91 patients who were included in the study. Fifty-one of these patients were $<65$ years old (mean age 43.2 years), and 40 patients were $\geq 65$ years old (mean age 80.9 years). The mean CT attenuation value in the younger cohort was $193.85 \mathrm{HU}$, whereas the mean CT attenuation value in the older cohort was 117.39 HU. The difference between these groups was statistically significant $(\mathrm{p}<$ 0.0001) (Table 1).

Using the threshold set for approximately $90 \%$ specificity ( $\leq 110$ or $>110 \mathrm{HU}), 6(12 \%)$ of 51 patients $<65$ years old had osteoporosis, and 13 (33\%) of the 40 older patients had osteoporosis. This difference was statistically significant $(\mathrm{p}=0.01)$ (Table 1$)$.

Using the threshold set for approximately $90 \%$ sensitivity $(\leq 160$ or $>160 \mathrm{HU}), 9(18 \%)$ of the 51 patients $<65$ years old had osteoporosis, and $36(90 \%)$ of the 40 patients aged $\geq 65$ years had osteoporosis. This difference was statistically significant $(\mathrm{p}<0.0001)$.

The third threshold used for differentiating osteoporosis from nonosteoporosis was set to achieve a balanced sensitivity and specificity. Using this threshold, 9 (18\%) of

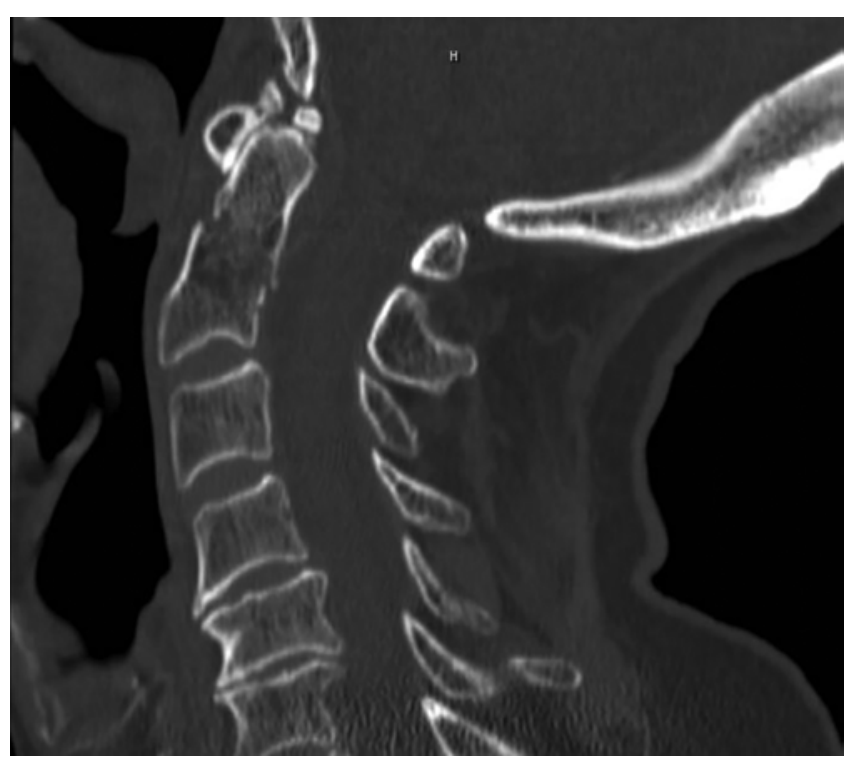

FIG. 3. A Type II odontoid fracture in an osteoporotic patient aged $>80$ years.

the 51 patients in the younger cohort had osteoporosis, and $26(65 \%)$ of the 40 patients in the older cohort had osteoporosis. Again, this difference was statistically significant ( $\mathrm{p}<0.0001)$ (Table 1).

Threshold values set to differentiate between normal and low BMD differed from those used to differentiate osteoporosis from nonosteoporosis. For approximately 90\% specificity, balanced specificity and sensitivity, and $90 \%$ sensitivity, the threshold values were 135,160 , and $190 \mathrm{HU}$, respectively. Using these values, the cohort of patients $<65$ years old seemed to have a CT attenuation that suggested, on average, normal BMD, regardless of which threshold was used. In contrast, the older cohort had abnormally low BMD. This result was accurate to a sensitivity and a specificity of approximately $90 \%$.

A subgroup of the 41 patients aged $\geq 65$ years with a C-2 fracture was analyzed further. In this group, 19 patients had a C-2 fracture, the mean age was 84.1 years, and the mean CT attenuation value was 109.8 HU (Table 2). This attenuation value is marginally lower than the threshold set for $90 \%$ specificity for distinguishing osteoporosis from nonosteoporosis. This $\mathrm{C}-2$ fracture subgroup was further subdivided such that only patients with a Type II odontoid fracture (a subgroup of C-2 fractures particularly common in older patients) were included. Eleven patients sustained a Type II odontoid fracture. Although the age threshold was $\geq 65$ years, the mean age was actually 86.8 years, and the mean CT attenuation value was 97.2 HU (Table 3), which is lower than the 110-HU threshold set for $90 \%$ specificity in differentiating osteoporosis from nonosteoporosis and lower than the mean observed CT attenuation value in all other groups of patients with a fracture of the cervical spine.

Correlation between age and BMD was good, with $\mathrm{r}^{2}$ values at the level of $\mathrm{C}-2$ and for subaxial fractures of -0.74 and -0.51 , respectively. The $\mathrm{r}^{2}$ value for the whole cohort combined was -0.62 . (Figs. 4-6). 
TABLE 1. CT attenuation values of patients with a cervical spine fracture according to age group

\begin{tabular}{lccc}
\hline & \multicolumn{2}{c}{ Age Group } & \multirow{2}{*}{ p Value } \\
\cline { 2 - 3 } BMD (HU) & $<65$ Yrs $(n=51)$ & $\geq 65$ Yrs $(n=40)$ & $8.7 \times 10^{-15}$ \\
\hline Mean (SD) & $193.85(42.67)$ & $117.39(39.12)$ & 0.01 \\
\hline$\leq 110$ & 6 & 13 & \multirow{2}{*}{$4.7 \times 10^{-6}$} \\
\hline$>110$ & 45 & 27 & \\
\hline$\leq 135$ & 9 & 26 & $1.53 \times 10^{-12}$ \\
\hline$>135$ & 42 & 14 & \\
\hline$\leq 160$ & 9 & 36 & \\
\hline$>160$ & 42 & 4 & \\
\hline
\end{tabular}

\section{Discussion}

Using CT attenuation, we have shown that a significant proportion of older patients who sustain a fracture of the cervical spine have osteoporosis. Recommendations by the US Surgeon General encourage DXA screening for osteoporosis in older patients. ${ }^{5}$ However, the literature indicates that this screening happens infrequently. ${ }^{16}$ Therefore, the opportunistic use of CT attenuation in the L-1 vertebra of patients with cervical spine fractures may help identify osteoporosis and enable appropriate management of osteoporosis to potentially reduce the incidence of repeat fractures. In addition, the magnitude of osteoporosis, which is a consideration in deciding the modality of management, can be assessed rapidly by using CT attenuation. The extent of difference in the levels of CT

TABLE 2. CT attenuation values of patients $\geq 65$ years old with a C-2 fracture

\begin{tabular}{cccccc}
\hline & & & \multicolumn{3}{c}{ CT Attenuation Value $(\mathrm{HU})$} \\
\cline { 5 - 6 } Patient No. & Age $(\mathrm{yrs})$ & ROI Area $\left(\mathrm{mm}^{2}\right)$ & Mean & Max & Min \\
\hline 1 & 84.4 & 485 & 55.6 & 233 & -70 \\
\hline 2 & 83 & 434 & 115.4 & 593 & -306 \\
\hline 3 & 77.1 & 473 & 150.3 & 574 & -210 \\
\hline 4 & 89.8 & 475 & 127.6 & 475 & -116 \\
\hline 5 & 85.8 & 384 & 136.5 & 275 & 49 \\
\hline 6 & 84.6 & 488 & 115.1 & 471 & -36 \\
\hline 7 & 86.3 & 371 & 59.8 & 407 & -207 \\
\hline 8 & 89.4 & 419 & 38 & 230 & -32 \\
\hline 9 & 75.6 & 444 & 139.2 & 605 & -271 \\
\hline 10 & 89.8 & 475 & 127.6 & 475 & -116 \\
\hline 11 & 83.4 & 508 & 120 & 778 & -385 \\
\hline 12 & 91.7 & 432 & 91.4 & 393 & -261 \\
\hline 13 & 95.3 & 367 & 52.2 & 284 & -146 \\
\hline 14 & 76.4 & 331 & 147.2 & 493 & -118 \\
\hline 15 & 76 & 469 & 124 & 438 & -162 \\
\hline 16 & 82.7 & 442 & 145.3 & 571 & -44 \\
\hline 17 & 83.1 & 459 & 96.5 & 304 & -33 \\
\hline 18 & 81 & 467 & 87 & 461 & -270 \\
\hline 19 & 82.4 & 426 & 158.4 & 453 & -116 \\
\hline Mean & 84.1 & 439.4 & 109.8 & 448.1 & -150 \\
\hline & & & & & \\
\hline
\end{tabular}

TABLE 3. CT attenuation values of patients $\geq 65$ years old with a Type II odontoid fracture

\begin{tabular}{cccccc}
\hline & & & \multicolumn{3}{c}{ CT Attenuation Value $(\mathrm{HU})$} \\
\cline { 4 - 6 } Patient No. & Age $(\mathrm{yrs})$ & ROI Area $\left(\mathrm{mm}^{2}\right)$ & Mean & Max & Min \\
\hline 1 & 84.4 & 485 & 55.6 & 233 & -70 \\
\hline 2 & 83 & 434 & 115.4 & 593 & -306 \\
\hline 3 & 89.8 & 475 & 127.6 & 475 & -116 \\
\hline 4 & 85.8 & 384 & 136.5 & 275 & 49 \\
\hline 5 & 84.6 & 488 & 115.1 & 471 & -36 \\
\hline 6 & 86.3 & 371 & 59.8 & 407 & -207 \\
\hline 7 & 89.4 & 419 & 38 & 230 & -32 \\
\hline 8 & 89.8 & 475 & 127.6 & 475 & -116 \\
\hline 9 & 95.3 & 367 & 52.2 & 284 & -146 \\
\hline 10 & 82.7 & 442 & 145.3 & 571 & -44 \\
\hline 11 & 83.1 & 459 & 96.5 & 304 & -33 \\
\hline Mean & 86.8 & 436.3 & 97.2 & 392.5 & -96.1 \\
\hline
\end{tabular}

attenuation, when comparing the age-stratified cohorts, quantitatively demonstrates the role of age-related bone loss in acute fractures of the cervical spine, especially at the level of C-2 in older patients. Across all 3 threshold levels (90\% sensitivity, $90 \%$ specificity, and balanced sensitivity and specificity), the mean value for CT attenuation consistently indicated a nonosteoporotic state in younger patients. Conversely, in older patients, low BMD was pronounced when compared with the thresholds for $90 \%$ sensitivity $(160 \mathrm{HU})$ and for balanced sensitivity and specificity. Measuring across various thresholds helped demonstrate the strength of this new technique in elucidating bone density across our study population; in addition, CT attenuation offers a greater degree of sensitivity and specificity than DXA, thereby increasing confidence in the data presented.

Although CT attenuation may share a similarity with quantitative CT (QCT) techniques in that they both use CT to generate images, QCT is a technically more challenging process that requires specialized software that may not always be available outside of academic centers. In addition, in clinical practice, the predictive value of $\mathrm{CT}$ attenuation is stronger than that of QCT. CT attenuation provides a relatively quick process for obtaining numeric values for bone density. The clinical availability and applicability of CT attenuation may likely result in greater utility of this approach.

In younger patients, 9 (approximately 18\%) of 51 had osteoporosis according to CT attenuation. This finding was unexpected. However, because the patients in this study had sustained a fracture, underlying impaired bone quality may explain the occurrence of such a fracture in a relatively young person. Because osteoporosis can be silent in its early stages, a simple screening method may allow patients with osteoporosis to be identified early, affording them the opportunity to commence prophylactic treatment.

Most cervical spine fractures in older patients occur at the level of C-2, 1,3,8,14,22,24,31,33 usually in the patient's 8th or 9 th decade of life. A subgroup review of the patients in our 


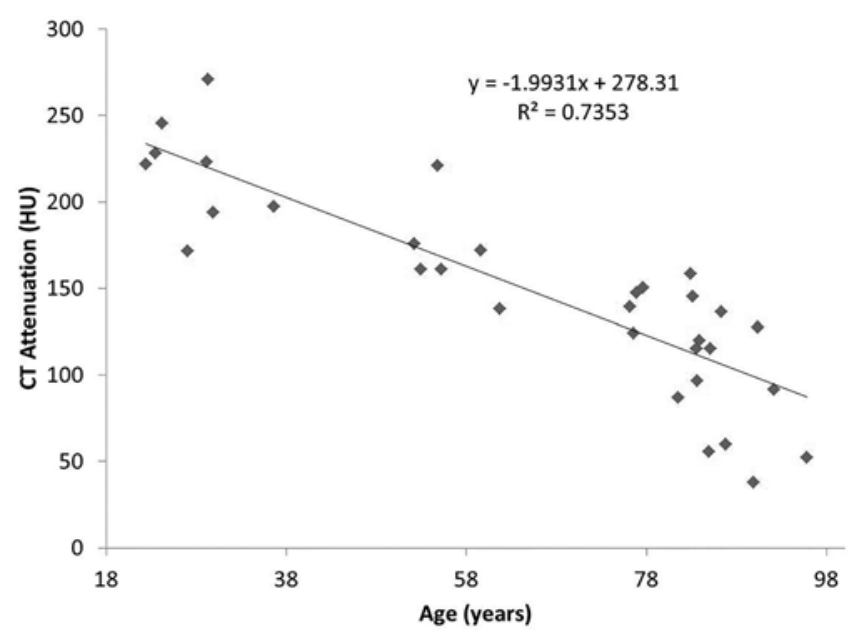

FIG. 4. Correlation between age and CT attenuation value in patients with a C-2 fracture.

series suggested that aging plays a strong role in the loss of bone leading to fractures, especially in Type II odontoid fractures (Figs. 1 and 3). Although previous research has explored the association of odontoid fractures in elderly patients with osteoporosis, ${ }^{11,12,19,33}$ those studies were largely based on a gross examination of CT scans of the axis at the dens-body junction, the odontoid process itself, and the body of the axis..$^{11,12,33}$ Although those studies provided extremely useful information on a localized process of bone loss, no data objectively correlate these descriptive findings with quantitative overall BMD in the body.

Our study correlates, for the first time, the presence of an age-related Type II odontoid fracture and reduced BMD (that can be correlated to a DXA scan). These fractures were particularly prominent among older patients, because they accounted for half of all C-2 fractures and one-fourth of the cervical spine fractures in our cohort. When compared with the overall cohort of patients aged $\geq$ 65 years, the reduction in the mean $\mathrm{CT}$ attenuation value in those patients with a C-2 fracture was noteworthy. As the age of the patients increased (the mean age of the patients aged $\geq 65$ years with a cervical spine fracture was 80.9 years and their mean CT attenuation value was 117.39 HU), the bone density decreased (the patients with a Type II odontoid fracture had a mean age of 86.8 years and a mean CT attenuation value of $97.2 \mathrm{HU}$ ). Figures $4-6$ show the progressive loss of bone density as correlation coefficients. To our knowledge, no other study has, to date, enumerated the progression on BMD in this specific group of patients. Although osteoporosis is primarily a clinical diagnosis, with a fragility fracture being pathognomonic for its presence, the current technique offers an assessment of the degree of bone loss at a level of granularity that previously was unavailable

Because older patients account for an increasing proportion of the population, the frequency with which these injuries occur will increase. ${ }^{21}$ The approaches to managing C-2 fractures can be particularly challenging because, given the frailty of many of these patients, there are divergent views on how aggressive the management should be.

Despite advances in guidelines, surgical techniques,

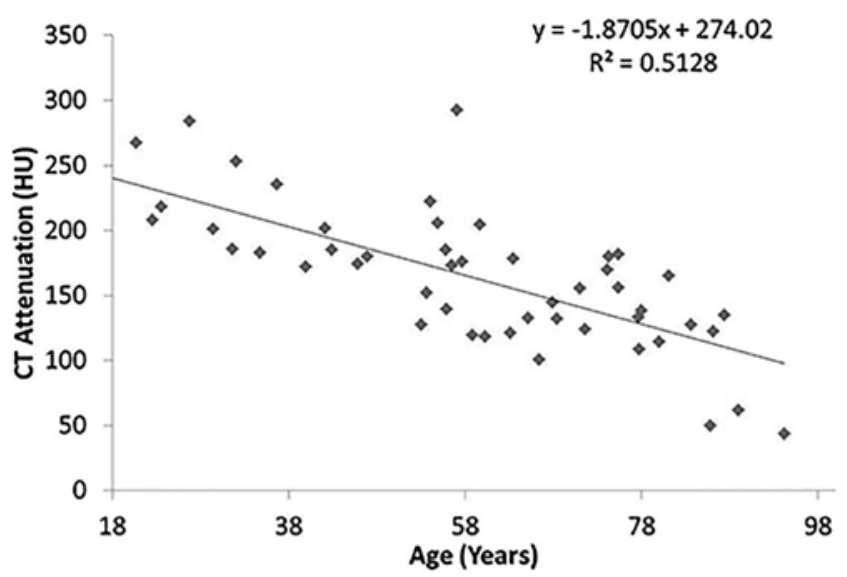

FIG. 5. Correlation between age and CT attenuation value in patients with a subaxial fracture of the cervical spine.

and imaging, the optimal approach to the management of elderly patients with a Type II odontoid fracture remains an area of controversy. ${ }^{28}$ This is a significant problem, because previous studies have shown a greater level of morbidity and death in older patients. 2,4,6,17,18,32 The debate is particularly prominent in regard to older patients with a Type II fracture with limited displacement. In this population, the risk-benefit consideration of a surgical or nonsurgical approach may be more equivocal given the increase in the complexity of these patients' overall medical and comorbidity profile. In elderly patients with a C-2 fracture, the mortality rates have been reported in some series at $>50 \% .8,14,22,24$ Therefore, elucidating approaches to improving outcomes or informing the discussion of the best management of this group of patients is important. One of the largest series of patients with a Type II odontoid fracture found that, in patients aged 65-74 years, surgical intervention was associated with a reduced mortality rate, although the advantage conferred by surgery in this series became more equivocal as patient age increased. ${ }^{30} \mathrm{~A}$ dichotomy exists between surgical and nonsurgical management of Type II odontoid fractures. Although some experts have documented very good clinical outcomes with

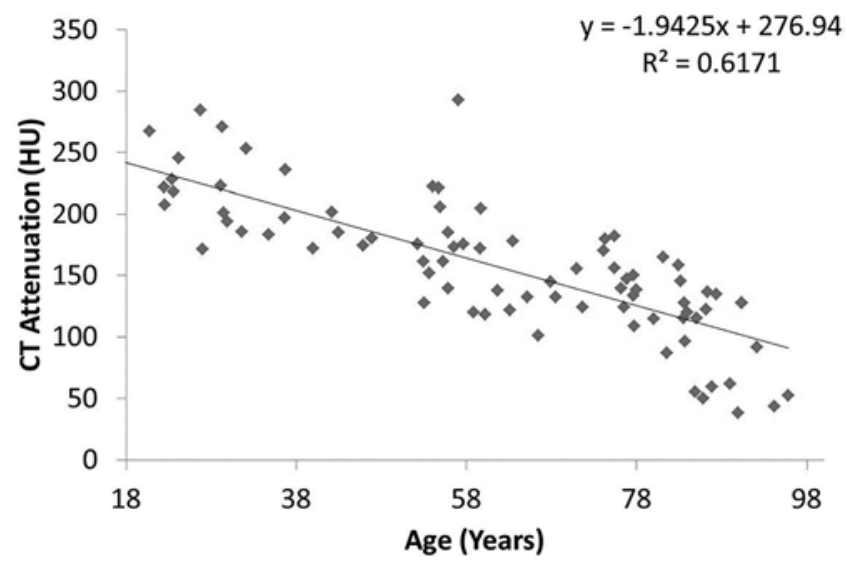

FIG. 6. Correlation between age and CT attenuation value in all patients with a fracture of the cervical spine aggregated. 
the use of halo braces in patients with these fractures, ${ }^{17,30}$ the halo vest was also associated with death and morbidity in several studies, , $^{1422,26,27,31,32}$ and some authors question the ability of older patients to tolerate these devices. ${ }^{28}$ Regardless of the treatment modality, in-hospital mortality rates for patients with a Type II odontoid fracture remain significant at $10 \%{ }^{28}$ to $25 \% .^{9,32}$ The significance of localized osteoporosis in the outcome of surgically stabilized Type II odontoid fractures has been demonstrated, ${ }^{19,21}$ with less robust healing observed in a more osteoporotic cohort; osteoporotic bone was observed to promote the formation of a cone-shaped excavation around the screw shank, which may reduce anchorage of the screw at the densbody junction. ${ }^{21}$ Although the current update to the guidelines issued by the Joint Section on Disorders of the Spine and Peripheral Nerves of the American Association of Neurological Surgeons and the Congress of Neurological Surgeons makes no specific mention of osteoporosis, ${ }^{28,29}$ the guidelines issued in $2002^{7}$ referenced an article that identified severe osteoporosis as a contraindication to anterior screw fixation; CT attenuation allows rapid and quantitative characterization of the severity of bone loss.

\section{Conclusions}

The use of CT attenuation to provide a global assessment of the quality of bone stock, based on L-1 bone density, is now available to virtually every clinician with access to picture-archiving and communication system software. It may be useful in planning the management of patients, regardless of age, who sustain a fracture of the cervical spine to improve patient outcomes.

\section{Acknowledgment}

We thank Mary Van Beusekom, ELS, for help in the review and correction of this manuscript.

\section{References}

1. Bednar DA, Parikh J, Hummel J: Management of type II odontoid process fractures in geriatric patients; a prospective study of sequential cohorts with attention to survivorship. J Spinal Disord 8:166-169, 1995

2. Bialas M, Stone M: Osteoporosis, in Pathy MSJ (ed): Principles and Practice of Geriatric Medicine. Chichester, UK: Wiley, 1988, pp 1225-1227

3. Chen YR, Boakye M, Arrigo RT, Kalanithi PS, Cheng I, Alamin T, et al: Morbidity and mortality of C2 fractures in the elderly: surgery and conservative treatment. Neurosurgery 70:1055-1059, 2012

4. Chutkan NB, King AG, Harris MB: Odontoid fractures: evaluation and management. J Am Acad Orthop Surg 5:199-204, 1997

5. Department of Health and Human Services: Bone Health and Osteoporosis: A Report of the Surgeon General. Rockville, MD: Office of the Surgeon General, 2004

6. Frangen TM, Zilkens C, Muhr G, Schinkel C: Odontoid fractures in the elderly: dorsal $\mathrm{C} 1 / \mathrm{C} 2$ fusion is superior to halovest immobilization. J Trauma 63:83-89, 2007

7. Hadley MN, Walters BC, Grabb PA, Oyesiku NM, Przybylski GJ, Resnick DK, et al: Guidelines for the management of acute cervical spine and spinal cord injuries. Clin Neurosurg 49:407-498, 2002

8. Hanigan WC, Powell FC, Elwood PW, Henderson JP: Odontoid fractures in elderly patients. J Neurosurg 78:3235,1993

9. Huelke DF, Nusholtz GS: Cervical spine biomechanics: a review of the literature. J Orthop Res 4:232-245, 1986

10. Klotzbuecher CM, Ross PD, Landsman PB, Abbott TA III, Berger M: Patients with prior fractures have an increased risk of future fractures: a summary of the literature and statistical synthesis. J Bone Miner Res 15:721-739, 2000

11. Lakshmanan P, Jones A, Howes J, Lyons K: CT evaluation of the pattern of odontoid fractures in the elderly-relationship to upper cervical spine osteoarthritis. Eur Spine J 14:78-83, 2005

12. Lakshmanan P, Jones A, Lyons K, Howes J: How significant is osteoporosis in producing odontoid fractures in the elderly? J Bone Joint Surg Br 88 (Suppl II):220, 2006

13. Lomoschitz FM, Blackmore CC, Mirza SK, Mann FA: Cervical spine injuries in patients 65 years old and older: epidemiologic analysis regarding the effects of age and injury mechanism on distribution, type, and stability of injuries. AJR Am J Roentgenol 178:573-577, 2002

14. Majercik S, Tashjian RZ, Biffl WL, Harrington DT, Cioffi WG: Halo vest immobilization in the elderly: a death sentence? J Trauma 59:350-358, 2005

15. Majumdar SR, Leslie WD: Conventional computed tomography imaging and bone mineral density: opportunistic screening or "incidentaloporosis"? Ann Intern Med 158:630-631, 2013

16. Majumdar SR, McAlister FA, Johnson JA, Bellerose D, Siminoski K, Hanley DA, et al: Interventions to increase osteoporosis treatment in patients with 'incidentally' detected vertebral fractures. Am J Med 125:929-936, 2012

17. Malik SA, Murphy M, Connolly P, O'Byrne J: Evaluation of morbidity, mortality and outcome following cervical spine injuries in elderly patients. Eur Spine J 17:585-591, 2008

18. Müller EJ, Wick M, Russe O, Muhr G: Management of odontoid fractures in the elderly. Eur Spine J 8:360-365, 1999

19. Nagashima H, Morio Y, Hasegawa K, Teshima R: Odontoid fractures complicated by fractures of the posterior arch of the atlas in the elderly over 85 years with severe thoracic kyphosis secondary to osteoporosis. Injury 32:501-504, 2001

20. Ngo B, Hoffman JR, Mower WR: Cervical spine injury in the very elderly. Emerg Radiol 7:287-291, 2000

21. Osti M, Philipp H, Meusburger B, Benedetto KP: Analysis of failure following anterior screw fixation of Type II odontoid fractures in geriatric patients. Eur Spine J 20:1915-1920, 2011

22. Pepin JW, Bourne RB, Hawkins RJ: Odontoid fractures, with special reference to the elderly patient. Clin Orthop Relat Res (193): 178-183, 1985

23. Pickhardt PJ, Pooler BD, Lauder T, del Rio AM, Bruce RJ, Binkley N: Opportunistic screening for osteoporosis using abdominal computed tomography scans obtained for other indications. Ann Intern Med 158:588-595, 2013

24. Platzer P, Thalhammer G, Ostermann R, Wieland T, Vécsei $\mathrm{V}$, Gaebler C: Anterior screw fixation of odontoid fractures comparing younger and elderly patients. Spine (Phila Pa 1976) 32:1714-1720, 2007

25. Regenbogen VS, Rogers LF, Atlas SW, Kim KS: Cervical spinal cord injuries in patients with cervical spondylosis. AJR Am J Roentgenol 146:277-284, 1986

26. Ryan MD, Henderson JJ: The epidemiology of fractures and fracture-dislocations of the cervical spine. Injury 23:38-40, 1992

27. Ryan MD, Taylor TK: Odontoid fractures in the elderly. $\mathbf{J}$ Spinal Disord 6:397-401, 1993

28. Ryken TC, Hadley MN, Aarabi B, Dhall SS, Gelb DE, 
Hurlbert RJ, et al: Management of isolated fractures of the axis in adults. Neurosurgery 72 (Suppl 2):132-150, 2013

29. Ryken TC, Hadley MN, Walters BC, Aarabi B, Dhall SS, Gelb DE, et al: Radiographic assessment. Neurosurgery 72 (Suppl 2):54-72, 2013

30. Schoenfeld AJ, Bono CM, Reichmann WM, Warholic N, Wood KB, Losina E, et al: Type II odontoid fractures of the cervical spine: do treatment type and medical comorbidities affect mortality in elderly patients? Spine (Phila Pa 1976) 36:879-885, 2011

31. Spivak JM, Weiss MA, Cotler JM, Call M: Cervical spine injuries in patients 65 and older. Spine (Phila Pa 1976) 19:2302-2306, 1994

32. Tashjian RZ, Majercik S, Biffl WL, Palumbo MA, Cioffi WG: Halo-vest immobilization increases early morbidity and mortality in elderly odontoid fractures. J Trauma 60:199_ 203, 2006

33. Watanabe M, Sakai D, Yamamoto Y, Sato M, Mochida J: Upper cervical spine injuries: age-specific clinical features. J Orthop Sci 15:485-492, 2010

34. White AA III, Panjabi MM: The basic kinematics of the hu- man spine. A review of past and current knowledge. Spine (Phila Pa 1976) 3:12-20, 1978

\section{Author Contributions}

Conception and design: Emohare, Morgan, Switzer, Polly. Acquisition of data: Emohare, Dittmer. Analysis and interpretation of data: Emohare, Dittmer. Drafting the article: Emohare, Switzer. Critically revising the article: Morgan, Switzer, Polly. Reviewed submitted version of manuscript: all authors. Approved the final version of the manuscript on behalf of all authors: Emohare. Statistical analysis: Emohare. Administrative/techni$\mathrm{cal} /$ material support: Dittmer, Morgan, Polly. Study supervision: Polly.

\section{Correspondence}

Osa Emohare, Department of Neurological Surgery, Regions Hospital, 640 Jackson St., Mail Stop 11503L, St. Paul, MN 55101. email: oemohare@umn.edu. 